\title{
Duas espécies novas de Plebeia Schwarz do Brasil (Hymenoptera, Apidae, Meliponinae) ${ }^{1}$
}

\author{
Jesus Santiago Moure ${ }^{2,3}$
}

${ }^{1}$ Contribuição $n^{\circ} 1442$ do Departamento de Zoologia, Universidade Federal do Paraná.
${ }^{2}$ Departamento de Zoologia, Universidade Federal do Paraná. Caixa Postal 19020, 81531-980 Curitiba-PR, Brasil. Endereço eletrônico:
jsmoure@bol.com.br
${ }^{3}$ Bolsista do CNPq.

\begin{abstract}
Two new species of Plebeia Schwarz from Brazil (Hymenoptera, Apidae, Meliponinae). Plebeia lucii sp. nov. (Minas Gerais) and P. phrynostoma sp. nov. (Espírito Santo) are described and illustrated. The original nest of $P$. lucii sp. nov. was collected near the campus of the Universidade Federal de Viçosa, Minas Gerais, and that of P. phrynostoma sp. nov. in Venda Nova do Imigrante, Espírito Santo. Both the nests were brought to the apiary of the Universidade Federal de Viçosa-MG where they are maintained.
\end{abstract}

KEYwORDs. Apidae; descriptions; nest entrance and structure; Plebeia; taxonomy.

Resumo. Duas espécies novas de Plebeia Schwarz, 1938 são descritas e ilustradas: $P$. lucii sp. nov. (Minas Gerais) e $P$. phrynostoma sp. nov. (Espírito Santo). O ninho original de P. lucii sp. nov. foi coletado perto do campus da Universidade Federal de Viçosa, Minas Gerais, e o de P. phrynostoma sp. nov. em Venda Nova do Imigrante, Espírito Santo. Ambos os ninhos foram trazidos para o apiário da Universidade Federal de Viçosa, onde estão sendo mantidos.

Palavras-chave. Apidae; descrições; entrada e estrutura do ninho; Plebeia; taxonomia.

As abreviações $\mathbf{T}$ e $\mathbf{E}$ correspondem, respectivamente, a tergo e esterno; dp significa distância entre os pontos. Esta distância comparada ao diâmetro dos pontos é dada em centésimos de milímetro; as outras distâncias, às vezes colocadas entre parênteses, são dadas em milímetros ou, em certos casos, em micra $(\mu)$, a não ser que haja outra indicação. DZUP - Coleção de Entomologia Pe. J. S. Moure, Departamento de Zoologia, Universidade Federal do Paraná, Curitiba-PR, Brasil.

\section{Plebeia lucii sp. nov.}

(Figs. 1, 2, 5-7)

Pertence ao grupo de espécies com o ninho em cachos (Fig. 2) e entrada em tubo muito curto e estreito (Fig. 1).

Operária. Comprimento total aproximado $3,00 \mathrm{~mm}$; da asa anterior 3,08 $\mathrm{mm}$; largura da cabeça $1,38 \mathrm{~mm}$; do T2 $1,18 \mathrm{~mm}$.

Preta, com os seguintes desenhos amarelos (Figs. 5-7): as estrias justa-orbitais subindo até os $3 / 5$ da órbita, estreitadas para cima, no terço inferior ligeiramente mais largas que o diâmetro do flagelo (10:9), sem contudo encher a área parocular inferior abaixo da fóvea tentorial; clípeo com uma vaga estria ao longo do meio (às vezes tênue, ou faltando) e uma pequena mancha triangular em cada um dos cantos inferiores, um pouco alongadas para o meio no bordo inferior e uma fina faixa marginando o bordo anterior; um grande trapézio na área supraclipeal; o labro e as mandíbulas, estas com estreita barra preta basal e outra escura mais estreita acompanhando o bordo marginal; uma mancha minúscula na área malar; todo o escapo anteriormente, em alguns exemplares (imaturos) ferrugíneo. No tórax, a faixa pronotal curtamente interrompida no meio e encurtada aos lados sem atingir os lobos pronotais; estes igualmente amarelos; as estrias laterais do mesoscuto, um pouco mais estreitas que as orbitais e um pouco atenuadas para a frente (Fig. 7), bastante encurtadas, para trás quase atingindo as axilas; estas inteiramente amarelas; uma estreita faixa acompanhando todo bordo posterior do escutelo, atenuada para os lados. As pernas anteriores e médias com a maior parte dos fêmures fusco-castanha deixando amarela a porção apical bem como os trocanteres; os basitarsos com uma vaga faixa escura; as pernas posteriores pretas com o terço basal das tíbias e os tarsômeros distais amarelos.

Pilosidade toda branca, mesmo quando vista de perfil, curtíssima, deixando o tegumento a descoberto na face; os pêlos mais longos no vértice até $120 \mu$, nos cantos anteriores do mesoscuto e no escutelo até $160 \mu$; moderada nas genas e um pouco menos densa nos mesepisternos; os pelinhos ao longo do sulco médio do mesoscuto como que repartidos para os lados; no escutelo mais escassa; nas pernas inteiramente branca incluso as cerdas corbiculares, as maiores chegando a $250 \mu$ (100x); nos flancos do propódeo mais densamente plumosas.

Pontuação muito peculiar pela implantação um pouco granulosa dos pêlos, principalmente no clipeo e na fronte, os intervalos, cerca de 1,5 dp, microrrugosos vistos com 100x; no escutelo os pontinhos mais escassos, separados por intervalos microrrugosos, um pouco maiores que no mesoscuto (cerca 
de 2 dp); nos mesepisternos a pontuação como no mesoscuto. Nos flancos do propódeo um pouco menos marcados. T1-2 lisos e brilhantes, na margem de $\mathrm{T} 2 \mathrm{com}$ micropontos e essa área micropontuada aumentando nos seguintes tergos, tendo nos intervalos entre os pontos finíssimas rugas transversais.

Cabeça mais larga que longa $(1,38: 1,18)$; comprimento e largura do olho 94:36 com a interorbital máxima quase como o comprimento do olho (88:93:68); a distância clípeo-ocelar quase duas vezes o comprimento do clípeo (71:36); escapo um pouco mais longo que 3,6 vezes o seu diâmetro (24:7), o flagelo e pedicelo juntos quase quatro vezes esse comprimento e o diâmetro do segundo flagelômero 9 vezes, os pelinhos do escapo com um comprimento cerca da metade do diâmetro do mesmo escapo. A distância interalveolar pouco mais de dois diâmetros do ocelo médio, a ocelorbital 1,5 vezes (28:18:Ø12); a carena preoccipital praticamente nula. Escutelo quase semicircular, ligeiramente mais curto que a metade da sua largura (58:28). Área basal do propódeo microrrugosa, as rúgulas nítidas (100x) um pouco onduladas, no meio um pouco arqueadas para trás, as centrais mais fortes dando ao conjunto um aspecto áspero. Tíbias posteriores um pouco mais longas que duas vezes a sua largura máxima (94:40), o basitarso um pouco mais longo que duas vezes a sua largura (54:24), com o bordo posterior pouco arqueado e o distal ligeiramente côncavo, com o vértice do canto posterior arredondado. O T1 liso e brilhante, $\mathrm{T} 2$ com alguns pontinhos pilígeros, mais evidentes aos lados, nos dois seguintes a parte basal lisa e brilhante a apical quase de igual largura com micropontos pilígeros, mais numerosos nos seguintes.

Holótipo. BRASIL. Minas Gerais: Viçosa, III-1998 (DZUP). Parátipos: dez exemplares com os mesmos dados do holótipo (DZUP).

Como os ninhos estão vivos, com abelhas ativas, e mantidos no apiário do Prof. Lúcio A. de Oliveira Campos (Universidade Federal de Viçosa-MG), será fácil conseguir mais exemplares.

O ninho, já na caixa de estudo, não possui invólucro e as células estão dispostas em forma de cachos (Fig.2). A entrada, em tubinho estreito e pouco saliente com bem menos de $1 \mathrm{~cm}$ (Fig.1) é, em geral, guardada apenas por uma operária. As campeiras com as colorações preta e amarela bem destacadas; a estria ao longo do meio do clípeo fraca, às vezes quase desaparecendo, ficando o disco do clípeo todo escuro (Figs.5 e 7). O abdome todo preto, sem faixas basais amarelas (Fig. 6).

Esta espécie foi descoberta pelo Prof. Lúcio A. de Oliveira Campos, da Universidade Federal de Viçosa, Minas Gerais, a quem dedico a espécie.

\section{Plebeia phrynostoma sp. nov.} (Figs. 3, 4)

Pertence ao grupo de espécies com o ninho em favos superpostos e cobertos por lâminas de cera e, tem de peculiar, uma entrada em longa fenda transversal (Fig. 4) formando a abertura estreita da colmeia.
Operária pequena com o comprimento total aproximado de $3,7 \mathrm{~mm}$; a asa anterior de $3,6 \mathrm{~mm}$; largura e comprimento da cabeça 1,6:1,4 mm; largura do T2 1,40 mm.

Preta, com desenhos amarelos bem desenvolvidos (Fig.3): estrias orbitais nos $2 / 5$ inferiores mais largas que o diâmetro do escapo $(1,6: 1,0)$ quase subparalelas às órbitas, depois no terço médio tão larga como o escapo, estreitando-se para cima e terminando mais adelgaçada aos 5/7 da órbita, cobrindo abaixo das fóveas tentoriais toda área parocular. $\mathrm{O}$ clípeo amarelo com uma larga faixa apical um pouco mais escura e sem a estria preta no bordo apical porém com um pouco de fusco aos lados da barra média cremosa (há alguma variação de acordo com a maturidade dos exemplares); um trapézio imperfeito na área supraclipeal; todo o labro amarelo e também a grande parte da mandíbula, esta com mancha preta basal e levemente parda na porção distal e com o bordo escuro acompanhando as margens superior e apical, incluso os dentes da mandíbula; todo escapo amarelo. No tórax são amarelos o pronoto e os lobos pronotais; as estrias laterais do mesoscuto um pouco mais estreitas que o diâmetro do escapo, quase chegando ao bordo anterior e tocando as axilas; estas inteiramente amarelas; o escutelo cremoso e com todo o bordo posterior marginado de um amarelo mais vivo. As tégulas amarelo-translúcidas com uma estria oblíqua amarela; as asas hialinas, iridescentes; a venação e estígma mais para o ocráceo. As pernas anteriores e médias amarelentas, as posteriores com a metade distal e os basitarsos um pouco pardos. Abdome amarelo, com as margens de T1-5 pardo-escuras; no T2,(no tergito com cerca de $0.35 \mathrm{~mm}$ desde o grádulo à margem apical, a faixa parda marginal ocupa cerca de $1 / 3=0.116 \mathrm{~mm}$ desse comprimento), em T3-5 a faixa marginal continua com a mesma largura diminuindo a faixa amarela basal; em $\mathrm{T} 1$ a faixa parda mais bem definida, um pouco alargada para o meio com as margens do desenho pardo convergentes e o ápice da convergência quase atingindo o bordo da cavidade basal.

Pilosidade curta e esbranquiçada na face, sem chegar a cobrir os espaços lisos; um pouco mais densa nas genas, porém os pêlos muito curtos; no vértice os pêlos mais longos com aproximadamente 100-120 $\mu$; no escapo curtos, cerca de um terço do diâmetro do escapo $(40 \mu)$. No mesoscuto semelhantes aos da fronte, com pêlos mais longos e plumosos nos cantos anteriores $(140 \mu)$ e no escutelo, alguns até $240 \mu$; nos mesepisternos mais claramente curto-plumosos. No propódeo a área basal praticamente glabra e nos flancos com a plumosidade mais evidente. T1 inteiramente glabro; T2 na faixa marginal com alguns pelinhos esparsos; em T3 e seguintes na faixa marginal com o pontilhado e pilosidade progressivamente mais desenvolvidos; T6 todo esparsamente piloso.

Pontuação toda pilígera; na fronte com intervalos lisos um pouco mais de 2dp; muito parecida nas paroculares; mais densa abaixo da depressão e ao longo do sulco frontal; no clípeo e supraclipeal igual, com alguns pontinhos cerdígeros mais evidentes; nas genas um pouco mais densa. No mesoscuto bastante semelhante à da fronte, os intervalos lisos cerca de 2 $\mathrm{dp}$; no escutelo mais esparsa, chegando os intervalos a 4-5 dp 

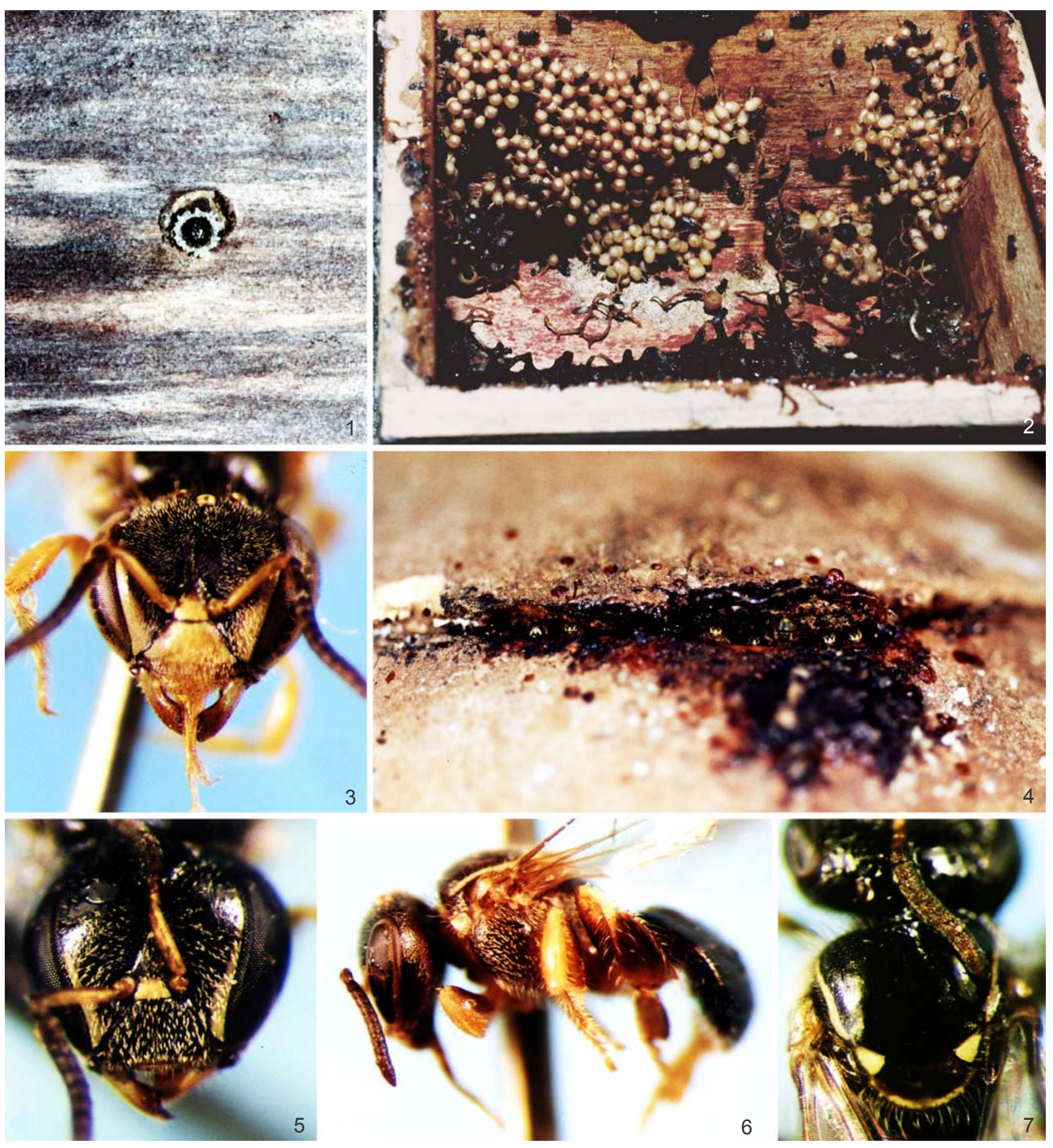

Figs. 1-7. Plebeia lucii sp. nov. 1, tubo de entrada do ninho; 2, interior do ninho. Plebeia phrynostoma sp. nov. 3, vista frontal da cabeça; 4, entrada do ninho. Plebeia lucii sp. nov. 5, cabeça; 6, vista lateral; 7, vista dorsal.

no disco; nos mesepisternos como no mesoscuto, porém um pouco mais granulosa parecendo mais densa; nos metepisternos mais delicada. No propódeo, a área basal e atrás sem pontos; nos flancos moderada; ao longo do meio da área basal uma saliência estreita, alongada e bem delimitada por fino sulco, ligada basalmente a uma série grande de carênulas basais. Os três primeiros tergos muito lisos na base e com micro-aréolas muito delicadas, esbatidas, na margem do T1; a parte basal amarela lisa e polida, a marginal com uma faixa parda; as faixas pardas em T2-3 fracamente transverso- 
canaliculadas; em T4-5 a base amarela lisa, o canaliculado mais evidente na faixa parda apical.

Cabeça (Fig. 3) mais larga que longa (160:140); comprimento e largura do olho 110/48; a interorbital máxima um pouco maior que o comprimento do olho (106:112:80); distâncias interocelares (28:24: o diâmetro do ocelo médio 16); com uma forte carena preoccipital bastante para baixo atrás do vértice e das genas; clípeo tão longo como a metade da sua distância ao ocelo médio (40:80); mandíbulas bidentadas e entre os dentículos o recorte em arco; o labro abaulado; o escapo das antenas pouco menos longo que seis vezes seu diâmetro (56:10) e os pelinhos esparsos pouco mais longos que um terço do diâmetro do flagelo, a distância alveolocelar 70 . Escutelo muito curto, cerca de três vezes mais largo que longo (12:35), em arco muito rebaixado. Célula marginal aberta no ápice (120:36) e o estigma moderado (65:14); as asas posteriores com 5 hâmulos. Tíbias posteriores quase quatro vezes sua largura (115:30; os basitarsos duas vezes mais longos que largos (60:30), com o bordo posterior mais recurvo na metade distal e o canto posterior arredondado. A área basal do propódeo um pouco mais longa como o escutelo, tendo, ao longo do meio e quase chegando à borda posterior, uma saliência estreita bem delimitada por fino sulco, alargada basalmente e ligada a uma série de carênulas basais convergentes para sua base e quase chegando ao bordo apical.

Holótipo. BRASIL. Espirito Santo: Venda Nova do Imigrante (BR262), 06-VI-1993, D. S. Aidaz (DZUP). Parátipos: 14 exemplares com os mesmos dados do holótipo; 3 de Paraju, ao noroeste de Domingos Martins, ES, 05/III/1967, Antenor Ramos Pinto (DZUP).

Os ninhos (Colônia 135) estão sendo mantidos no campus da Universidade Federal de Viçosa, MG, Departamento de Biologia Geral, "Apiário do Prof. Lúcio de Oliveira Campos".

Esta espécie recebe, nos Estados do Espírito Santo e de Minas Gerais, o nome de "boca de sapo", devido ao formato da entrada do ninho, em longa fenda transversal (Fig. 4). Esta denominação popular sugeriu-nos o nome dado à espécie "phrynostoma", de origem grega que significa: phrynós = sapo + stoma $=$ boca.

Ainda que pequenas, são abelhas muito agressivas. Basta tocar no tronco deitado onde está o ninho para que saiam em grande número em busca do agressor; embora não possam causar dano, por não terem ferrão, são muito incômodas quando se agarram ao cabelo.

Agradecimentos. Meus agradecimentos pela leitura e correções do original ao Prof. Albino Morimasa Sakakibara; pelas fotos dos tipos à Favísia Freitas de Oliveira e pelas fotos dos ninhos, revisão final do texto e rearranjo da estampa ao Prof. Gabriel A. R. Melo.

Recebido em 19.VIII.2003; aceito em 20.I.2004 